\title{
Proceedings
}

\section{Comparative Evaluation of Inspection Techniques for Decay Detection in Urban Trees ${ }^{\dagger}$}

\author{
Salvatore F. Papandrea*, Andrea R. Proto, Maria F. Cataldo and Giuseppe Zimbalatti \\ Department of AGRARIA, University of Reggio Calabria, Feo di Vito snc, 89122, Reggio Calabria, Italy; \\ salvatore.papandrea@unirc.it (S.F.P.), andrea.proto@unirc.it (A.R.P.), maria.cataldo@unirc.it (M.F.C.), \\ gzimbalatti@unirc.it (G.Z.) \\ * Correspondence: salvatore.papandrea@unirc.it; Tel.: +39 (0) 965.1694275 \\ + Presented at the 1st International Electronic Conference on Forests, 15-30 November 2020; \\ Available online: https://sciforum.net/conference/IECF2020
}

Published: 25 October 2020

\begin{abstract}
Green areas in cities are acquiring an increasingly important role in urban architecture. However, a crucial problem associated with urban trees is the need to know and evaluate the health of plants in order to ensure the safety and security of citizens. One important process consists of the technical assessment of conditions of standing trees, in order to prevent falling due to strength failure or damage caused by internal decay. In recent years, investigations with non-destructive techniques on urban trees have shown great success in detecting internal decay, which, depending on the severity of the case, makes the stability of the entire plant or parts of it precarious. This study reports the results of an inspection protocol that combines single-path stress wave timer and micro drilling resistance, to detect internal defects on Melia trees (Melia azedarach L.) located in the city of Reggio Calabria, Southern Italy.
\end{abstract}

Keywords: VTA; acoustic velocity; sound wood; drilling.

\section{Introduction}

Green areas in cities are acquiring an increasingly important role in urban architecture. Within an urban community, trees are valuable assets providing ecological, aesthetic, social, and economic benefits, but, at the same time, they pose a potential risk to people and property when they become structurally unstable [1]. A crucial problem associated with urban trees is the need to know and evaluate the health of plants in order to ensure the safety and security of citizens. Accidents related to the fortuitous fall of branches and trees always keep the attention of administrations and individuals alive on the problem of tree safety. As a result, the detection, evaluation, and management of hazardous trees has become a major concern for urban foresters and park managers [2]. For this reason, the theories and application protocols for evaluating the stability of trees are the subject of a wide debate involving researchers and technicians. A thorough inspection of the tree's branches, stem, and root collar is essential in detecting hazardous conditions [2]. Visual Tree Assessment (VTA) is an internationally recognized procedure for tree health assessment. The method involves three phases: $i$ ) visual inspection; ii) any instrumental investigation carried out on subjects who highlight the presence of structural defects; iii) assignment of the subsidence propensity class or phytostatic risk categories; iv) definition of operational note to restore the static balance of the tree or, in extreme cases, to recommend its felling. Visual inspection aims at identifying on all the visible components of the tree, symptoms indicative of structural defects that can compromise its stability. The instrumental investigation describes quantitatively the anomalies found. Instrumental analysis can make use of the different methods of investigation available: identification of discontinuities in tissues by means of sonic or ultrasonic systems, measurement of wood density with penetrometric 
systems, evaluation of the mechanical characteristics of wood with destructive tests, electrical resistivity, radar, and other techniques [3-8]. Concerns related to public safety support the development and application of rapid and precise diagnostic technologies to detect decay and other types of structural defects in trees [1]. A significant effort has been devoted to developing robust nondestructive technologies (NDT) that are capable of predicting the intrinsic wood properties of individual trees [9]. The assessment of wood via stress waves is one of the oldest and simplest methods available [10]. Acoustic methods have been found to be very effective for detecting the internal decay of urban trees [11]. The concept of detecting decay using ultrasound or sound waves is based on the observation that stress wave propagation is sensitive to the presence of degradation in wood [12]. In general, stress waves travel faster in high-quality wood than in deteriorated and lowquality wood $[13,14]$. A typical approach for measuring wave propagation velocity in standing trees involves inserting two sensor probes (a transmit probe and a receiver probe) into the sapwood and introducing stress wave energy into the tree trunk from a point source through a hammer impact [15]. This procedure is referred to as a single-path stress wave timing measurement, and the stress wave velocity obtained suggests the physical condition of the tree. The single-path method is fast, economical, and easy. The health of a tree can be assessed also by means of penetrometers and drilling resistometers. Micro drilling resistance measures the relative resistance (drilling torque) of the material as a rotating needle is driven into the wood at a constant speed and changes in wood resistance are displayed on a graph as changes in amplitude. Areas of prolonged low resistance indicate decay, cavities, or cracks [12]. Furthermore, drilling does not require the removal of the bark, and the width of the hole in the tree is barely visible.

The purpose of this study was to determine whether it is possible to classify the level of wood degradation with the use of simple, cheap and quick tools. The research reports the first results of applying an inspection protocol that combines single-path stress wave timer and resistance microdrilling to detect internal defects on large Melia trees (Melia azedarach L.). The relevance of this study is du because the Melia tree, despite being one of the most widespread species in urban arboriculture, has never been subjected to studies that describe the behaviour of sound waves within its woody tissues.

\section{Materials and Methods}

\subsection{Study Area}

The tests are conducted on 23 Melia (Melia azedarach L.) trees located along the edges of a street in the metropolitan city of Reggio Calabria (Italy) (Figure 1). This street is strongly characterized by the high flow of pedestrians who use the neighbouring seaport. Melia tree is one of the most widespread species in urban architecture. It is a small to medium, deciduous tree from 6 to 35 metres in height.

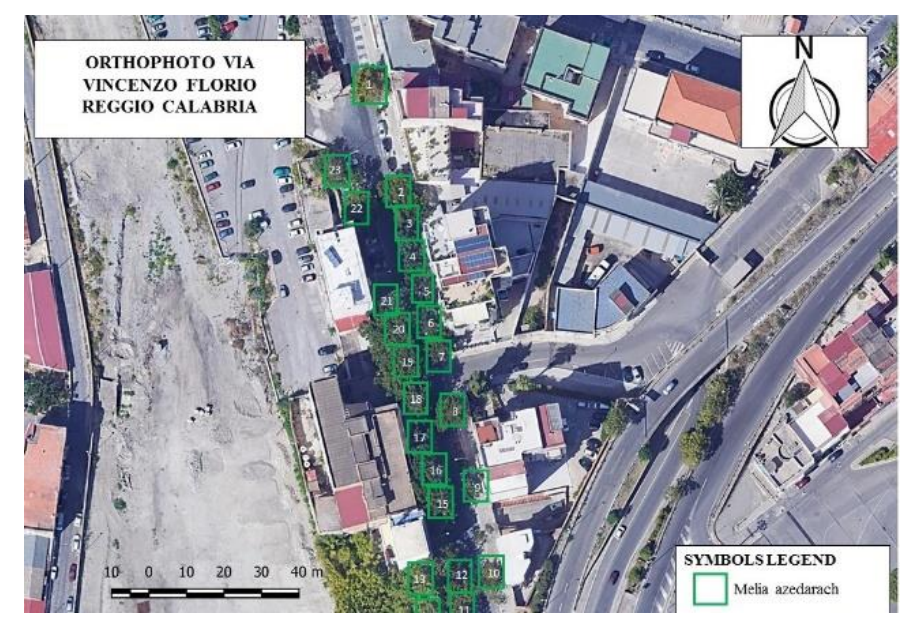

Figure 1. Study site in the metropolitan city of Reggio Calabria (Italy). 


\subsection{Test Devices}

\subsubsection{Microsecond Timer}

To investigate the health status, after a preliminary visual inspection, the trees have been subjected to a single-path stress wave test by means of a Fakopp Microsecond Timer (Fakopp Enterprise, Agfalva, Hungary). This tool consisting of needles attached to accelerometers, used as mediators, that penetrate the bark and reach the sapwood of a tree. A hammer is used to tap the start sensor to generate a stress wave into the tree stem in the radial direction. The two sensors pick up the start and stop signal, and the wave transmission time is displayed on an LCD screen with a resolution $\pm 1 \mu \mathrm{s}$. Following the instructions dictated by the manufacturer of the instrument (Fakopp Enterprise $\mathrm{Bt}$ ), the trunks were tested by aligning the two probes on the trunk in a level north-south position for the first test and in a level west-east position for a second test. The test was repeated several times for each couple of sensors to derive average value from at least three readings. Through the speed of the sound wave, it is possible to immediately establish whether in the area between the two sensors there is a cavity or degenerated wood. The principle on which the analysis is based is simple: if there is a cavity or degenerated wood between the two sensors, the sound waves produced by the impact of the hammer do not propagate along the straight line joining the sensors, but they go around the cavity remaining in the sound wood. In this way, there is a longer travel and the waves take a longer time to reach the sensor block [16-18].

\subsubsection{Resistograph Resi PD400}

A drilling resistance tool typically consists of a power drill unit, a small-diameter spade-type drill bit, and an electronic device that can be connected to the serial interface input of any standard personal computer. The tool is portable and is easy to handle in the field and in the lab, captures and reproduces digital and relatively high-resolution data. The method is based on measuring the drilling resistance along a small needle path when a needle is driven into a tree with a constant force. This system produces a chart showing the relative resistance over its travel path. This chart can be produced either as a direct printout or can be downloaded to a computer. Areas of sound wood have levels of resistance, with voids shoving no resistance. The user can determine areas of low, mild, and high levels of decay [19]. During the process of a drilling measurement, the relative drilling resistance, feeding force, and speed parameters can be measured continuously as a function of the drill bit position in the drilling path [20]. Micro drilling resistance test was conducted using a IML Resi PD400 (IML, Inc., Kennesaw, GA) equipped with $400 \mathrm{~mm}$-long and $3 \mathrm{~mm}$-thick steel drill (tip diameter $3 \mathrm{~mm}$, shaft diameter $1.5 \mathrm{~mm}$ ). Measurements were performed at the height of the defects found on the trees. The perforation was set at $2 \mathrm{~cm} / \mathrm{min}$ forward speed (feed speed) with 3500 rotation rate $(\mathrm{rpm})$ along the radial direction of the trees stem, producing a trace chart at a sampling interval of $0.1 \mathrm{~mm}$. Like the microsecond timer test, micro drilling resistance test, the trees were tested by drilling the trunk in a level north-south position for the first test and in a level west-east position for a second test. The test results were transmitted to a computer and processed with dedicated software.

\section{Data Processing and Analysis}

From the tests carried out by the Microsecond timer, the velocities of single-path stress waves (VUW) were obtained in a level north-south position (VUWNS) and in a level west-east position (VUWWE). The distance between the two sensors was used to calculate the propagation speed (in $\mathrm{m} / \mathrm{s}$ ) of the sound wave into the wood between the two sensors.

The software used for resistograph analysis was PD-tools Pro V. 1.22. Similar to other study [21], the extent of damaged zone determined by Resistograph (DZR) was computed in percentage (Eq. 1):

$$
\left.\mathrm{DZR}=\left(\mathrm{d}_{\mathrm{R}} / \mathrm{L}\right) \times 100 \quad[\%] \quad \text { (Eq. } 1\right)
$$

where $\mathrm{L}$ is the diameter of the tree at the height of the defect found $(\mathrm{mm})$ and $\mathrm{d} \mathrm{R}$ is the total length of significantly damaged zone of the tree $(\mathrm{mm})$. 
In particular, the damaged zones along the radial direction of trees were obtained in a level north-south position (DZRNS) and in a level west-east position (DZRWE). Results of the investigations were evaluated using a basic statistical analysis. Relationships between the velocities of single-path stress waves (VUW) and the damaged zones of trees (DZ), determined by Resistograph $(\mathrm{DZ})$, were evaluated using linear correlations [21]. Monitoring trees of the same age and same wood density, the distinction into various damage classes was classified using a threshold of $30 \%$ of wood deterioration, considering the average of the speeds recorded by the two paths carried out by the resistograph.

\section{Results and Discussion}

Basic descriptive statistics of the results are shown in the Table 1. Based on the extent of the damage found with the Resistograph, four damage classes (low, medium, high) have been defined with respect to the healthy wood class (Figure 2). Tight relationships were observed between the velocities of ultrasonic waves (VUW) and the damaged zones inside the trees determined by the Resistograph (DZR). The $\mathrm{R}^{2}$ coefficient for the linear correlation between DZRNS and VUWNS yielded a value of 0.809 (Figure 3), while the one in the west-east direction (DZRWE-VUWWE) got a value slightly above 0.910 . To know the correlation between the velocities of single-path stress waves and damaged zones on general level into the trunks section, an average was carried out by the northsouth and west-east data for both tests (Table 2). The result showed that the two factors were characterized of a high correlation. These correlations at the beginning view provide the opportunity for preliminary detection of defects in standing tree using only one inspection method, usually cheaper and faster, that is ultrasound method. This correspondence between two instrumentals methods is in agreement with the previous experiments of Costa et al. [22] who found relationships between the stress wave timer and visual damage analysis in woods of different wood species.

Table 1. Descriptive statistics.

\begin{tabular}{cccccc}
\hline & No. & Min. value & Max. value & Mean value & Standard deviation \\
\hline DZR $(\%)$ & 23 & 0.000 & 75.000 & 35.594 & 25.495 \\
VUW $(\mathrm{m} / \mathrm{s})$ & 23 & 0.830 & 1.830 & 1.355 & 0.328 \\
\hline
\end{tabular}

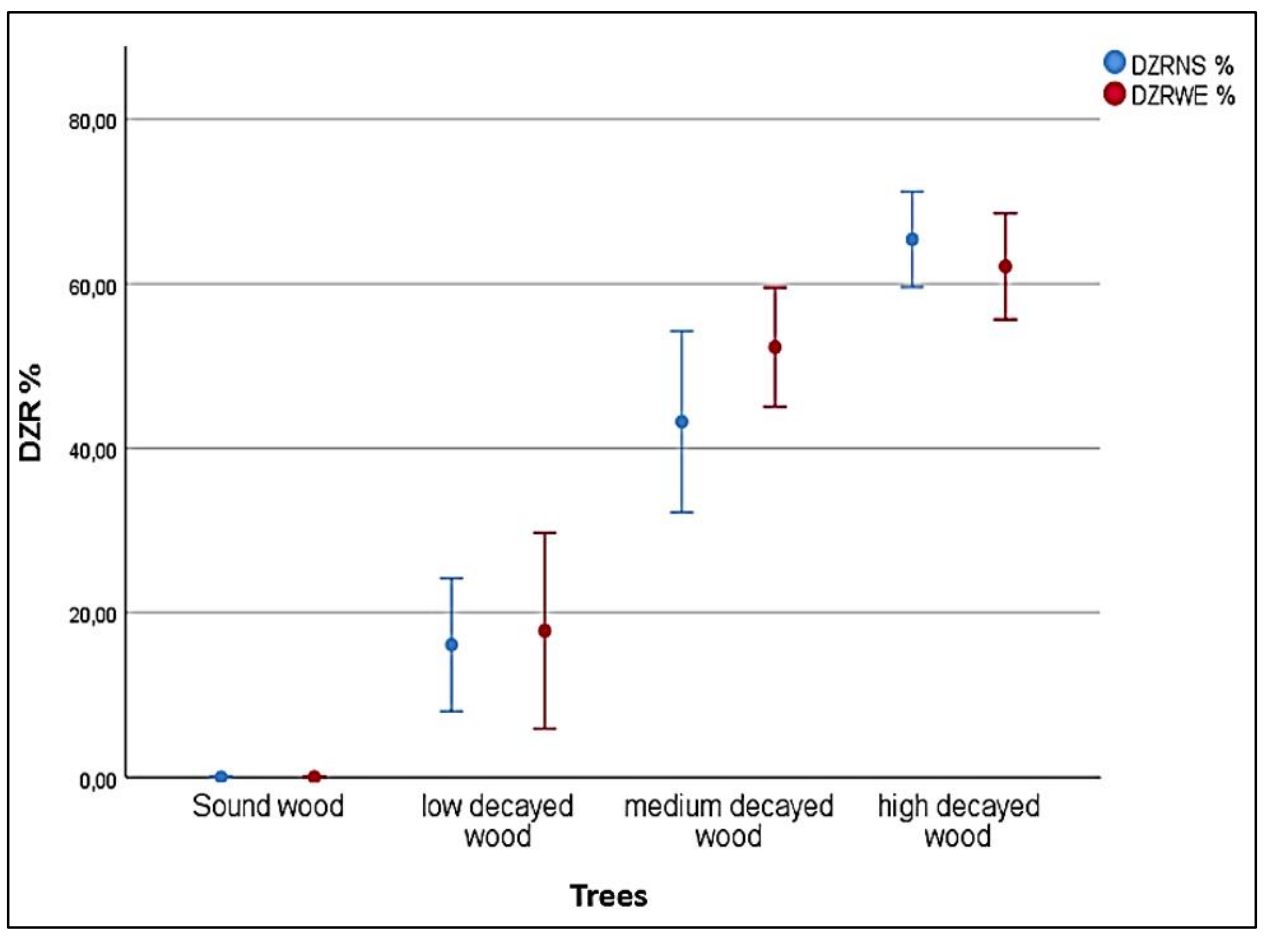

Figure 2. Distribution of trees within damage classes. 


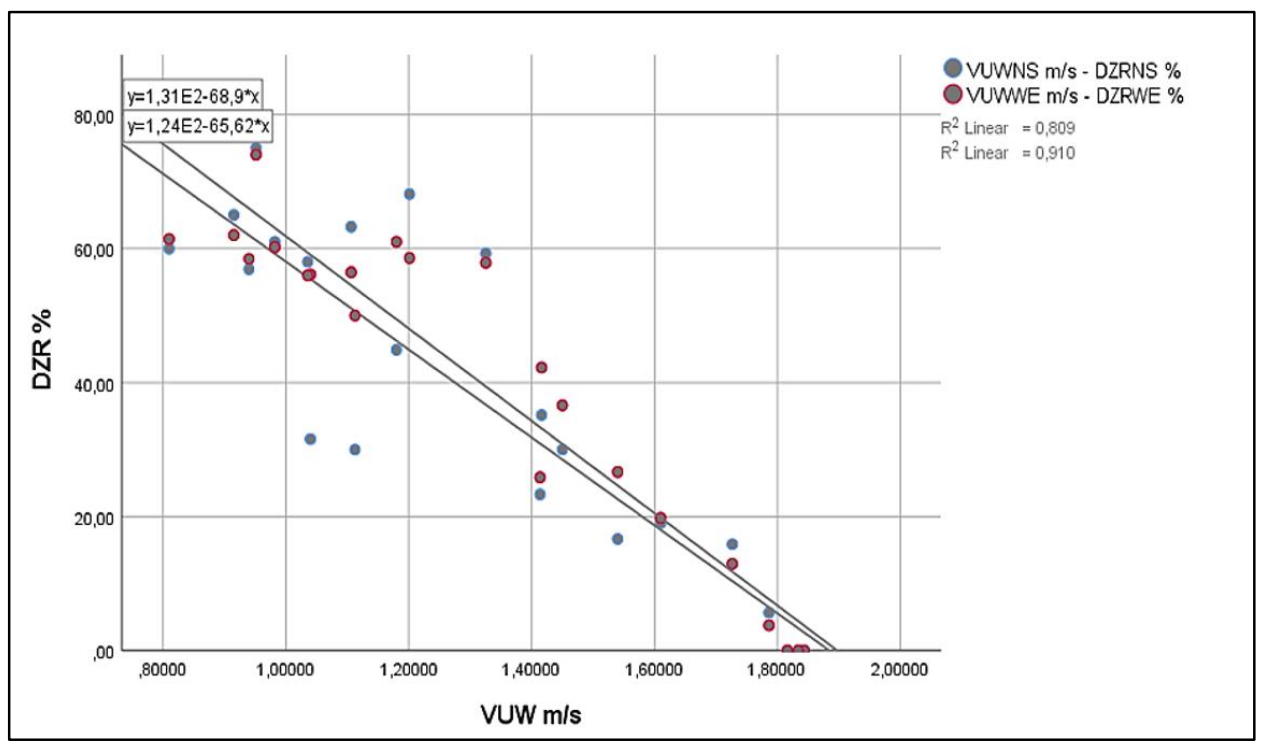

Figure 3. Statistical results.

Table 2. Damaged zones (DZR) and velocities of ultrasonic waves (VUW) correlation.

\begin{tabular}{lccc}
\hline & Pearson coefficient & $p$-value & Standard error \\
\hline DZR $(\%)$ - VUW $(\mathrm{m} / \mathrm{s})$ & $-0,956$ & 0.000 & 0,0731 \\
\hline
\end{tabular}

\section{Conclusions}

NDT of trees has received considerable attention in Europe. A variety of techniques, including drilling resistance, electrical impedance, ground penetrating radar, sound transmission, and mechanical tests are being utilized. If fact, these tools are considered necessary to evaluate the safety condition of urban forests. Green areas in cities are acquiring an increasingly important role in urban architecture. However, a crucial problem associated with urban trees is the need to know and evaluate the health of plants in order to ensure the safety and security of citizens. The study showed that the micro drilling and single path stress wave equipment identified the different sizes of defects. The impact hammer is the cheapest and most quickly used tool in investigating the health conditions of trees but does not permit reconstruction of the total cross-sectional area. In fact, single-path stress wave measurement can only detect internal decay that is greater than $20 \%$ of the total cross-section area [14] (Wang et al. 2007). Therefore, several measurements are needed to be able to detect defects in the entire study. The Resistograph is portable and is easy to handle in the field and in the lab. Furthermore, drilling does not require the removal of the bark, and the width of the hole in the tree is barely visible. So, the test using this tool is considered minimally invasive. Further studies would be advisable to investigate trees of lower diameter classes to obtain a range of greater details on the development of decay within the plant.

Author Contributions: A.R.P. and G.Z. conceived and designed the experiments; S.F.P. and M.F.C. performed the experiments; all authors analysed the data and wrote the paper; S.F.P. and M.F.C. contributed to the data analysis. S.F.P. is the corresponding author. All authors read and approved the final version of the manuscript.

Conflicts of Interest: The authors declare no conflict of interest.

\section{References}

1. Brashaw, B.K.; Bucur, V.; Divos, F.; Goncalves, R.; Lu, J.; Meder, R.; Pellerin, R.F.; Potter, S.; Ross, R.J.; Wang, X.; Yafang Y. Nondestructive testing and evaluation of wood: A worldwide research update. For. Prod. J. 2009, 59, 7-14.

2. Smiley, E.T.; Fraedrich, B.R.; Fengler, P.H. Hazard Tree Inspection, Evaluation, and Management. Handb. Urban Community For. Northeast 2000, 243-260, doi:10.1007/978-1-4615-4191-2_17. 
3. Wang, X.; Wiedenbeck, J.; Ross, R.J.; Forsman, J.W.; Erickson, J.R.; Pilon, C.; Brashaw, B.K. Nondestructive evaluation of incipient decay in hardwood logs. Gen. Tech. Rep. FPL-GTR-162. Madison, WI: US Dept. of Agriculture, Forest Service, Forest Products Laboratory 2005, 162., 11. http://www.fpl.fs.fed.us/documnts/fplgtr/fpl gtr162.pdf

4. Socco, L.V.; Sambuelli, L.; Martinis, R.; Comino, E.; Nicolotti, G. Feasibility of ultrasonic tomography for nondestructive testing of decay on living trees. Res Nondestruct Eval 2004, 15(1), 31-54.

5. Sambuelli, L.; Socco, L.V.; Godio, A.; Nicolotti, G.; Martinis, R. Ultrasonic, electric and radar measurements for living trees assessment. Bollettino di Geofisica Teorica ed Applicata (Bulletin of Theoretical and Applied Geophysicist) 2003, 44, 3-4: 253-279.

6. Bucur, V. Nondestructive characterization and imaging of wood. Berlin, Germany: Springer Verlag. 2003.

7. Tomikawa, Y.; Iwase, Y.; Arita, K.; Yamada, H. Nondestructive inspection of a wooden pole using ultrasonic computed tomography. IEEE T Ultrason Ferr 1986, 33(4), 354-358.

8. Proto, A.R.; Zimbalatti G.; Bernardi B. Nuovi strumenti al servizio delle utilizzazioni forestali [New tools for forest utilization]. In Proceedings of the Second International Congress of Silviculture. Italian Academy of Forest Sciences, Florence, Italy Florence 26-29 Nov 2014; Vol. 1, pp. 463-468. [in Italian] http://dx.doi.org/10.4129/2cis-arp-nuo

9. Proto, A.R.; Cataldo, M.F.; Costa, C.; Papandrea, S.F.; Zimbalatti, G. A tomographic approach to assessing the possibility of ring shake presence in standing chestnut trees. Eur. J. Wood Wood Prod. 2020, 78(6), 11371148. doi:10.1007/s00107-020-01591-0.

10. Vössing, K.J.; Niederleithinger, E. Nondestructive assessment and imaging methods for internal inspection of timber. A review. Holzforschung 2018, 72, 467-476, doi:10.1515/hf-2017-0122.

11. Feng, H.; Li, G.; Fu, S.; Wang, X. Tomographic Image Reconstruction Using an Interpolation Method for Tree Decay Detection. BioResources 2014, 9, 3248-3263.

12. Wang, X.; Allison, R.B. Decay detection in red oak trees using a combination of visual inspection, acoustic testing, and resistance microdrilling. Arboric. Urban For. 2008, 34, 1-4.

13. Divos, F; Szalai, L. Tree evaluation by acoustic tomography. In: Proceedings 13th international symposium on nondestructive testing of wood, 19-21 Aug 2002, Berkeley, CA, pp 251-256.

14. Wang, X.; Allison, R.B.; Wang, L.; Ross, R.J. Acoustic Tomography for Decay Detection in Red Oak Trees. Res. Pap. FPL-RP 642 Madison, WI, USDA, Forest Service, Forest Products Lab, 2007, 7.

15. Proto, A.R.; Macrí, G.; Bernardini, V.; Russo, D.; Zimbalatti, G. Acoustic evaluation of wood quality with a non-destructive method in standing trees: A first survey in Italy. IForest 2017, 10, 700-706, doi:10.3832/ifor2065-010.

16. Divos F.; Meszaros K., Root decay detection by stress wave technique. In proc. Of the first European Symposium on Nondestructive Testing, Sopron, Hungary 1994, 524.

17. Halabe, U.B.; Bidigalu G.M.; GangaRao H.V.S.; Ross P. Nondestructive evaluation of green wood using stress wave and transverse vibration techniques. Mater. Eval. 1997, 1013-1018

18. Wang, X.P.; Divos, F.; Pilon, C.; Brashaw, B.K.; Ross, R.J.; Pellerin, R.F. Assessment of decay in standing timber using stress wave timing nondestructive evaluation tools - a guide for use and interpretation. Gen. Tech. Rep. - USDA For. Serv. For. Prod. Lab. 2004, 12.

19. Ross, R.J. Nondestructive Testing and Evaluation of Wood. Nondestruct. Eval. Wood. Gen. Tech. Rep. FPLGTR-238 2015, 167.

20. Mattheck, C.; Bethge, K.; Albrecht, W. How to read the results of resistograph m. Arboric. J. 1997, 21, 331346, doi:10.1080/03071375.1997.9747179.

21. Reinprecht, L.; Šupina, P. Comparative evaluation of inspection techniques for impregnated wood utility poles: ultrasonic, drill-resistive, and CT-scanning assessments. Eur. J. Wood Wood Prod. 2015, 73, 741-751, doi:10.1007/s00107-015-0943-8.

22. Costa A.F.; Teles R.F., Goncalves J.C. Stress wave and visual analysis of treated and non-treated fence posts after 15 years in field test. IRG/WP 2010 10-20449, p 11.

Publisher's Note: MDPI stays neutral with regard to jurisdictional claims in published maps and institutional affiliations. 
(C) 2020 by the authors. Submitted for possible open access publication under the terms and conditions of the Creative Commons Attribution (CC BY) license (http://creativecommons.org/licenses/by/4.0/). 